See Article page 534 .

\section{Commentary: Battle of the bulge}

\section{Brian Mitzman, MD}

The infamous rectus bulge: An often seen but rarely reported complication after robotic assisted thoracoscopic surgery. ${ }^{1}$ Although a major benefit of thoracoscopy is the lack of rib spreading leading to less nerve trauma, transient neuralgia is often seen from irritation to the intercostal nerves. Any injury to T7 through T12 intercostal nerves can lead to paresthesia of the rectus, ${ }^{2}$ but a low assistant or extraction port that aggravates the lower intercostals (usually T9 and 10) can lead to a paralysis and flaccidity of the ipsilateral abdominal rectus muscle. Although often just an aesthetic issue, this bulge can lead to significant anguish in a patient. Wildemeersch and colleagues ${ }^{3}$ present a case of persistent rectus abdominis paralysis after roboticassisted lobectomy, and perform a deep dive into this pesky protuberance.

Wildemeersch and colleagues ${ }^{3}$ describe a 55-year-old male patient who underwent a robotic-assisted lobectomy. Ipsilateral rectus paralysis was noted within weeks of surgery, and at 1 year postoperatively, was still present. Quantitative measurements were performed including a computed tomography scan showing decreased muscle thickness compared with the contralateral side at the level of T12 (0.52 vs $1.2 \mathrm{~cm})$, along with decreased muscle density ( 29 vs $66 \mathrm{HU})$. An electromyography confirmed denervation of the upper two-thirds of the rectus and external oblique abdominal wall muscles.

What are the possibilities for nerve injury in this case? The authors utilize higher-than-normal port sites compared with many other centers, ${ }^{4}$ and the accessory port was only in the seventh intercostal space. Rectus paralysis from these

\footnotetext{
From the Division of Cardiothoracic Surgery, University of Utah Health, Salt Lake City, Utah.

Disclosures: The author reported no conflicts of interest.

The Journal policy requires editors and reviewers to disclose conflicts of interest and to decline handling or reviewing manuscripts for which they may have a conflict of interest. The editors and reviewers of this article have no conflicts of interest.

Received for publication Sept 29, 2021; revisions received Sept 29, 2021; accepted for publication Oct 13, 2021; available ahead of print Oct 24, 2021.

Address for reprints: Brian Mitzman, MD, Division of Cardiothoracic Surgery, University of Utah Health, 30 N 1900 E, \#3C127 SOM, Salt Lake City, UT 84132 (E-mail: brian.mitzman@hci.utah.edu).

JTCVS Techniques 2021;10:538-9

2666-2507

Copyright (C) 2021 The Author(s). Published by Elsevier Inc. on behalf of The American Association for Thoracic Surgery. This is an open access article under the CC BY-NC-ND license (http://creativecommons.org/licenses/by-nc-nd/4.0/).

https://doi.org/10.1016/j.xjtc.2021.10.026
}

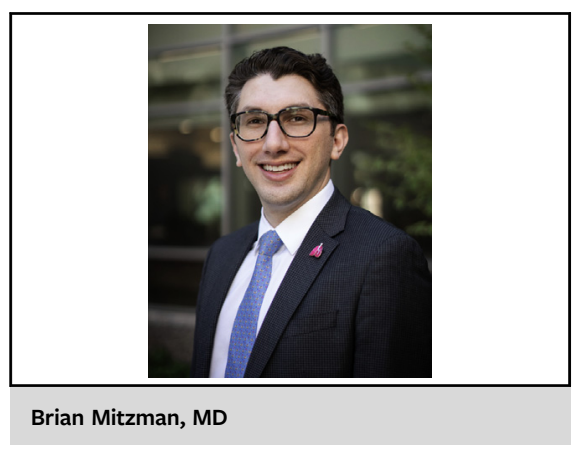

CENTRAL MESSAGE

Rectus paralysis is a known

complication after robotic

thoracic surgery, but is not well

described. Although often tem-

porary, patients should be

informed of this potential post-

operative issue.

port positions specifically would be unusual. The tumor was also fairly small $(1.7 \mathrm{~cm})$, so inadvertent rib spreading during extraction is unlikely. One unique aspect of this case was the utilization of cryoanalgesia, with cryoablation of intercostal nerves 6 through 8 . Could the cryoanalgesia be the culprit? It's certainly in the differential.

Anecdotally, we are seeing more rectus paralysis after robotic-assisted thoracoscopy compared with similar video-assisted thoracoscopic surgery cohorts. Although there is limited literature, evaluation of cross-sectional area of ipsilateral and contralateral rectus muscles has shown greater atrophy in robotic approach versus both robotic and open. ${ }^{5}$ At this time, there is not a great explanation for this higher incidence, except for differences in port placement or, theoretically, excess torque form the robotic arms on the intercostals. Although the patient in this case is still optimistically waiting for resolution, most of these rectus motor deficits do resolve in time. ${ }^{2}$

\section{References}

1. Timmermans L. Abdominal wall bulging after thoracic surgery, an underdiagnosed wound complication. Hernia. 2013;17:89-94.

2. Cho HM. Paralysis of the rectus abdominis muscle after a VATS. Ann Thorac Cardiovasc Surg. 2018;24:40-2.

3. Wildemeersch D, Yogeswaran SK, Vyncke G, Meeus I, Wielandt T, Hans G, et al. Upper rectus abdominis paralysis after robot-assisted thoracic oncology surgery with cryoanalgesia: a rare complication. J Thorac Cardiovasc Surg Tech. 2021; 10:534-7. 
4. Oh DS, Tisol WB, Cesnik L, Crosby A, Cerfolio RJ. Port strategies for robotassisted lobectomy by high-volume thoracic surgeons: a nationwide survey. Innovations. 2019;14:545-52.
5. Wang Y, Bhandari P, Trope W, Guenthart B. Greater ipsilateral rectus muscle atrophy after robotic thoracic surgery compared to open and vats approaches. J Am Coll Surg. 2020;231:S289. 